\section{Serum 25-hydroxyvitamin D levels are not associated with adverse outcomes in Clostridium difficile infection}

\author{
Dejan Micic, ${ }^{1}$ Krishna Rao, ${ }^{2,3}$ \\ Bruno Caetano Trindade, 2,4 \\ Seth T. Walk, ${ }^{2,3}$ Elizabeth Chenoweth, ${ }^{5}$ \\ Ruchika Jain, 2,3 Itishree Trivedi, ${ }^{2}$ \\ Kavitha Santhosh, ${ }^{2,3}$ Vincent B. Young, ${ }^{2-4}$ \\ David M. Aronoff ${ }^{2-4}$ \\ 'Division of Gastroenterology, \\ Hepatology and Nutrition, University of \\ Chicago, IL; ${ }^{2}$ Department of Internal \\ Medicine, ${ }^{3}$ Division of Infectious \\ Diseases, ${ }^{4}$ Department of Microbiology \\ and Immunology, University of Michigan \\ Health System, Ann Arbor, MI; \\ ${ }^{5}$ University of Michigan Medical School, \\ Ann Arbor, MI, USA
}

\section{Abstract}

Clostridium difficile infection (CDI) is a significant source of healthcare-associated morbidity and mortality. This study investigated whether serum 25-hydroxyvitamin D is associated with adverse outcomes from CDI. Patients with CDI were prospectively enrolled. Charts were reviewed and serum 25-hydroxyvitamin D was measured. The primary outcome was a composite definition of severe disease: fever (temperature $>38^{\circ} \mathrm{C}$ ), acute organ dysfunction, or serum white blood cell count $>15,000$ cells/ $\mu \mathrm{L}$ within 24-48 hours of diagnosis; lack of response to therapy by day 5 ; and intensive care unit admission; colectomy; or death within 30 days. Sixty-seven patients were included in the final analysis. Mean $( \pm$ SD) serum 25 hydroxyvitamin D was $26.1( \pm 18.54) \mathrm{ng} / \mathrm{mL}$. Severe disease, which occurred in 26 (39\%) participants, was not associated with serum 25-hydroxyvitamin D [odds ratio (OR) 1.00; $95 \%$ confidence interval (CI) 0.96-1.04]. In the adjusted model for severe disease only serum albumin (OR 0.12; 95\%CI 0.02-0.64) and diagnosis by detection of stool toxin (OR 5.87; 95\% CI 1.09-31.7) remained independent predictors. We conclude that serum 25 -hydroxyvitamin D is not associated with the development of severe disease in patients with CDI.

\section{Introduction}

Clostridium difficile infection (CDI) is a reemerging infectious disease with recent, signif- icant increases in incidence and mortality. ${ }^{1}$ In some communities, $C$. difficile has replaced methicillin-resistant Staphylococcus aureus (MRSA) as the most common healthcare-associated infection. ${ }^{2}$ Although studies have differentially focused on specific populations and outbreak settings, all-cause mortality has been estimated between 15-20\% and disease recurrence between $20-60 \%{ }^{1}$ Taken together, excess healthcare costs in the United States attributed to CDI in acute-care facilities has been estimated at $\$ 4.8$ billion in $2008 .{ }^{3}$ Current treatment recommendations include metronidazole for mild to moderate CDI and vancomycin for severe CDI. ${ }^{1}$ The increased burden of disease and risk of relapse has led to an interest in novel therapeutic approaches, such as rifaximin, fidaxomicin, cholestyramine, intravenous immunoglobulin, monoclonal antibodies and fecal transplantation. ${ }^{4}$ The full spectrum of CDI pathogenesis, interaction with the host immune response, risk factors for severe disease, and response to novel treatments remains to be elucidated. Vitamin D is a potent immunomodulatory secosteroid hormone. Vitamin D induction of the antimicrobial peptide cathelicidin and up-regulation of autophagy are proposed mechanisms for pathogen clearance. ${ }^{5,6}$ In community-acquired pneumonia, vitamin D deficiency was also found to be an independent predictor of 30-day mortality and Intensive Care Unit (ICU) admission. ${ }^{7}$ Vitamin D deficiency in CDI has been previously associated with increased healthcare costs, ${ }^{8}$ the development of hospital-acquired CDI, ${ }^{9}$ severe CDI (defined by computed tomography scan findings of colitis) $)^{10}$ and a combined outcome variable of death and lack of diarrhea resolution. ${ }^{11}$ However, the role of vitamin D in CDI and common variables of clinical disease severity has not been evaluated. This study tests the hypothesis that serum 25-hydroxyvitamin D at the time of CDI diagnosis is associated with severe clinical disease.

\section{Materials and Methods}

\section{Ethics statement}

This study was approved by the University of Michigan Institutional Review Board. Written informed consent for participation in this study was obtained from all patients.

\section{Population and setting}

The University of Michigan Health System includes a 930-bed tertiary care inpatient facility. The institution utilizes an electronic medical record system providing access to patient records. As previously described, ${ }^{12}$ non-pregnant inpatients $\geq 18$ years of age with diarrhea and positive testing for $C$. difficile in
Correspondence: David Aronoff, Division of Infectious Diseases, Vanderbilt University School of Medicine, A2200 MCN, 1161 21st Avenue South, Nashville, TN 37232-2582, USA.

Tel.: +1.615.322.8972 - Fax: +1.615.322.317

E-mail: d.aronoff@vanderbilt.edu

Key words: Vitamin D; Clostridium difficile; colitis; biomarkers.

Acknowledgments: we would like to thank the Marie Yu with the Department of Pharmacy Services, Cathrin Ring and Jill Mogle with the Division of Infectious Diseases and the University of Michigan Health System Medical Center Information Technology team for their assistance in data collection.

Contributions: DM, KR, VBY, DMA, conception and design, acquisition, analysis, or interpretation, drafting of manuscript; BCT, STW, EC, RJ, IT, $\mathrm{KS}$, contributed to acquisition, analysis, or interpretation, critical review of manuscript.

Conflict of interest: the authors declare no potential conflict of interest.

Funding: this work was supported by grants from the National Institutes of Health (grant numbers U19-AI090871，K01-AI097281，DK42086 and T32DK007074), the Claude D. Pepper Older Americans Independence Center (grant number AG-024824), and the Michigan Institute for Clinical and Health Research (grant number 2UL1TR000433). The funders had no role in study design, data collection and analysis, decision to publish, or preparation of the manuscript.

Received for publication: 2 April 2015.

Revision received: 26 June 2015 .

Accepted for publication: 26 June 2015.

This work is licensed under a Creative Commons Attribution NonCommercial 3.0 License (CC BYNC 3.0).

CC Copyright D. Micic et al., 2015

Licensee PAGEPress, Italy

Infectious Disease Reports 2015; 7:5979

doi:10.4081/idr.2015.5979

stool (described below) were enrolled within 72 hours of diagnosis (median 24 hours), from October 25, 2010 to March 29, 2011 and October 31, 2011 to April 4, 2012. Patients taking the hormonally active metabolite 1,25dihydroxycholecalciferol (calcitriol) were excluded as this was expected to influence the vitamin D status but is not measured by the 25-hydroxyvitamin D assay. ${ }^{7}$ After testing from the clinical laboratory was completed, discarded stool and serum were collected at enrollment and stored at $-80^{\circ} \mathrm{C}$ prior to sample processing. 


\section{Clostridium difficile and vitamin D testing}

Initial stool sample testing was performed at the discretion of the inpatient care teams. Stool samples were transported to the clinical microbiology laboratory at the University of Michigan in Cary-Blair media. The C. DIFF QUIK CHEK COMPLETE ${ }^{\circledR}$ test (Techlab, Inc. Blacksburg, VA, USA) for $C$. difficile glutamate dehydrogenase (GDH) and toxins A or B by enzyme immunoassay (EIA) was performed. All $\mathrm{GDH}+/$ toxin- stool tests were subjected to analysis for the $t c d B$ gene by real-time polymerase chain reaction (PCR) (BD GeneO $\mathrm{hm}^{\mathrm{TM}}$ Cdiff Assay, Franklin Lakes, NJ, USA). A positive result included samples that were $\mathrm{GDH}+/$ toxin+ by EIA or were $t c d B$ gene+ by PCR. Attempts to confirm positive $C$. difficile tests were made by anaerobic culture on taurocholate-cycloserinecefoxitin-fructose agar at $37^{\circ} \mathrm{C}$ and PCR, and strains were ribotyped using high-throughput, fluorescent PCR-ribotyping as described elsewhere..$^{13}$ Serum 25 -hydroxyvitamin D was measured in duplicate using a 25-hydroxyvitamin $\mathrm{D}$ enzyme-linked immunoassay (ELISA) (Calbiotech, Inc., Spring Valley, CA, USA).

\section{Clinical epidemiology}

Retrospective chart review and structured query of the electronic medical record was performed on all included participants blinded to the results of the serum 25-hydroxyvitamin D assay. The following variables were extracted by chart review: exogenous vitamin D supplementation (cholecalciferol) or 1,25-dihydroxycholecalciferol (calcitriol) use at the time of admission; residence in an extended care facility (ECF) prior to admission; and the surveillance definitions for the likely site of $C$. difficile acquisition, as recommended by McDonald et al. ${ }^{14}$ (community-associated CA) CDI [symptoms began in the community or within 48 hours of admission to the hospital provided that the onset of symptoms was greater than 12 weeks from a previous healthcare exposure] and healthcare facility-onset, healthcare facility-associated (HO-HA) CDI (symptoms beginning more than 48 hours after admission to the hospital). Structured query was used to collect the variables associated with demographics, vitals, laboratory values, medications, and co-morbid conditions. A Charlson-Deyo score was calculated using ICD-9 codes as described by Deyo et al.;15 weights from the original Charlson comorbidity index were assigned to the individual variables in the Deyo modification to create a modified Charlson-Deyo comorbidity index. ${ }^{16}$

\section{Outcome variables}

Severe disease was defined as white blood cell count (WBC) $>15,000$ cells $/ \mu \mathrm{L}$; fever (tem- perature $>38^{\circ} \mathrm{C}$ ), the presence of acute organ dysfunction (AOD) (acute kidney injury per RIFLE criteria, ${ }^{17}$ acute respiratory distress syndrome (if listed in the chart or meeting criteria of a Pa02/FiO2 $<200$ and diffuse pulmonary infiltrates with acute onset); new/worse heart failure (if listed in the chart); liver failure (new/worse coagulopathy or hepatic encephalopathy); and/or shock (systolic blood pressure $<90 \mathrm{mmHg}$ or need for pressors/inotropes); lack of response to initial therapy (defined as a need to change initial therapy or a lack of clinical response within 5 days of treatment initiation based on retrospective review); or 30-day ICU admission, colectomy, or death from the time of diagnosis and attributed to CDI as determined by two reviewers independently, with conflicts adjudicated by a third reviewer. Supplementary analysis included comparisons of mean serum 25-hydroxyvitamin D levels with age, gender, season, exogenous vitamin D supplementation and ECF residence.

\section{Statistical analysis}

Statistical analysis was conducted using the programs R 2.15.3 (http://www.r-project.org) and Graphpad Prism 6.02 (Graphpad Software, Inc., La Jolla, CA, USA). A two-tailed P value of 0.05 was considered significant. We used simple logistic regression to assess if variables,

Table 1. Baseline patient demographics, $C$. difficle characteristics, and laboratory markers at diagnosis for the overall cohort and quartiles of increasing serum 25-hydroxyvitamin D level.

\begin{tabular}{|c|c|c|c|c|c|}
\hline & Total cohort $(n=67)$ & Quartile 1 & Quartile 2 & Quartile 3 & Quartile 4 \\
\hline 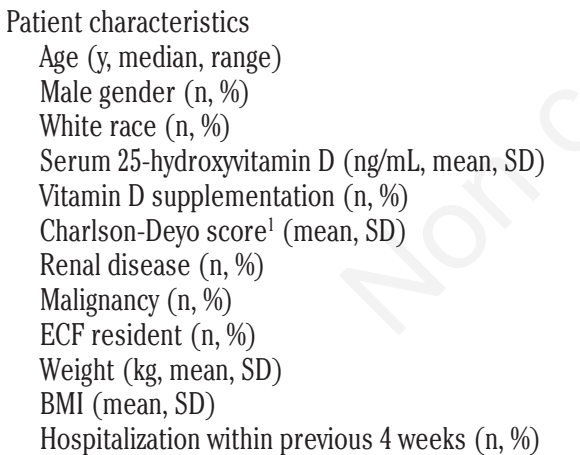 & $\begin{array}{c}59(20-88) \\
32(48) \\
58(87) \\
26.1(18.54) \\
21(31) \\
2(1.45) \\
9(13) \\
21(31) \\
13(19) \\
78.8(22.6) \\
27.3(7.7) \\
21(31)\end{array}$ & $\begin{array}{c}52(24-78) \\
8(47) \\
14(82) \\
12.27(1.16) \\
5(29) \\
1.82(1.74) \\
3(18) \\
2(12) \\
3(18) \\
84.1(28.3) \\
28.7(9.6) \\
3(18)\end{array}$ & $\begin{array}{c}56(25-87) \\
9(53) \\
16(94) \\
18.11(2.13) \\
5(29) \\
2.12(1.73) \\
2(12) \\
5(29) \\
4(24) \\
86.6(23.5) \\
30.9(8.9) \\
6(35)\end{array}$ & $\begin{array}{c}69(24-88) \\
10(63) \\
14(88) \\
24.43(1.86) \\
1(6) \\
1.75(1) \\
3(19) \\
6(38) \\
5(31) \\
74.5(16.9) \\
25.2(4.9) \\
7(44)\end{array}$ & $\begin{array}{c}62(20-81) \\
5(29) \\
14(82) \\
48.96(24.41) \\
10(59) \\
2.29(1.21) \\
1(6) \\
8(47) \\
1(6) \\
69.5(17.2) \\
24.6(4.9) \\
5(29)\end{array}$ \\
\hline $\begin{array}{l}\text { CDI characteristics } \\
\text { CA CDI (n, \%) } \\
\text { HO-HA CDI (n, \%) } \\
\text { Diagnosis by detection of stool toxin by EIA (n, \%) } \\
\text { Diagnosis by PCR for } t c d B(n, \%) \\
\text { Ribotype } 014-020(\mathrm{n}, \%) \\
\text { Ribotype } 027(\mathrm{n}, \%) \\
\text { Initial management with vancomycin }(\mathrm{n}, \%)\end{array}$ & $\begin{array}{c}9(13) \\
33(49) \\
33(49) \\
34(51) \\
10(15) \\
6(9) \\
24(36)\end{array}$ & $\begin{array}{c}2(12) \\
10(59) \\
9(53) \\
8(47) \\
2(12) \\
2(12) \\
6(35)\end{array}$ & $\begin{array}{l}2(12) \\
8(47) \\
9(53) \\
8(47) \\
2(12) \\
2(12) \\
4(24)\end{array}$ & $\begin{array}{l}3(19) \\
9(56) \\
9(56) \\
7(44) \\
3(19) \\
1(6) \\
9(56)\end{array}$ & $\begin{array}{c}2(12) \\
6(35) \\
6(35) \\
11(65) \\
3(18) \\
1(6) \\
5(29)\end{array}$ \\
\hline 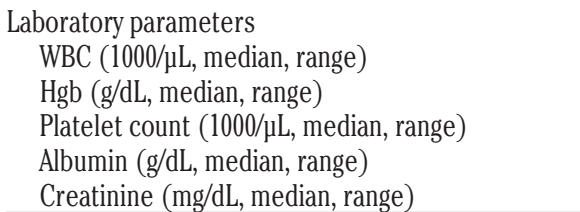 & $\begin{array}{l}10.3(0.2-66.4) \\
9.5(6.5-15.4) \\
259(19-1145) \\
3.3(1.9-4.6) \\
0.9(0.4-5.2)\end{array}$ & $\begin{array}{l}12.2(4.6-56.3) \\
8.8(7.4-15.4) \\
286(56-664) \\
2.9(1.9-4) \\
1.1(0.4-4)\end{array}$ & $\begin{array}{l}9.8(0.8-45.1) \\
9.3(7.2-13.1) \\
284(83-524) \\
3.4(2.8-4.6) \\
1.1(0.7-5.2)\end{array}$ & $\begin{array}{c}10.1(0.2-66.4) \\
8.3(6.5-11.8) \\
256(19-1145) \\
3.3(2.4-4.3) \\
1(0.6-4.4)\end{array}$ & $\begin{array}{c}7.1(1.3-18.3) \\
10.1(7.1-14.2) \\
196(38-593) \\
3.6(2.7-4.4) \\
0.7(0.5-1.6)\end{array}$ \\
\hline
\end{tabular}

BMI, body mass index in $\mathrm{kg} / \mathrm{m}^{2}$; CA, community-associated; CDI, Clostridium difficile infection; ECF, extended care facility; EIA, enzyme immunoassay; Hgb, hemoglobin; HO-HA, healthcare facility-onset, healthcare facility-associated; PCR, polymerase chain reaction; SD, standard deviation; $y$, years. 1weighted comorbidity index. 
including serum 25-hydroxyvitamin D level, were associated with disease severity. Serum 25-hydroxyvitamin D level, variables found to be significant on univariate analysis, and those with a priori clinical significance were included in the final multivariable model. Variations in the serum 25-hydroxyvitamin D including log transformation and characterization as a categorical variable were performed in the final model without difference in the strength of association; therefore modeling as a continuous variable was presented in the final model. Mean serum 25-hydroxyvitamin D levels were compared between various categories (gender, age, season, ECF residence, and exogenous vitamin D use) and significance testing was performed using the unpaired $t$ test.

\section{Results}

\section{Characteristics of the study popula- tion}

There were 69 patients initially enrolled, however two patients were excluded for use of 1,25-dihydroxycholecalciferol (calcitriol) on admission leaving 67 patients included in the final analysis. Median age was 59 (range 2088 ) years. Demographic and clinical data are shown in Table 1. Mean ( \pm SD) serum 25 hydroxyvitamin D was $26.1( \pm 18.54) \mathrm{ng} / \mathrm{mL}$. Thirty-two (48\%) of the participants were male and 21 (31\%) were receiving vitamin D supplementation at the time of hospital admission. Twenty-one (31\%) were hospitalized within the previous 28 days and the comorbid conditions of renal disease and malignancy were present in 9 (13\%) and 21 (31\%) study participants, respectively. Average length of hospital stay was $11( \pm 9)$ days. Thirty-three (49\%) CDI episodes were HO-HA and vancomycin was the initial treatment choice in 24 (36\%) participants.

\section{Severe disease}

Twelve (18\%) cases of CDI did not respond to initial therapies and 11 (16\%) patients had a WBC $>15,000$ cells $/ \mathrm{mm}^{3}$ within 24 hours of CDI. Death, colectomy and ICU admission attributable to CDI within 30 days of diagnosis occurred in 1 (1\%), 1 (1\%), and $5(7 \%)$ patients, respectively. The primary composite outcome of severe disease occurred in 26

Table 2. Unadjusted and adjusted logistic regression analysis for independent predictors of severe disease.

\begin{tabular}{|c|c|c|c|c|}
\hline Characteristic & Unadjusted OR (95\%CI) & $\mathbf{P}$ & Adjusted OR (95\%CI) & $\mathbf{P}$ \\
\hline Age (years) & $1.03(1-1.05)$ & 0.057 & $1(0.95-1.05)$ & 0.921 \\
\hline Male gender & $1.15(0.43-3.1)$ & 0.770 & $1.36(0.18-10.5)$ & 0.765 \\
\hline Serum 25-hydroxyvitamin D (ng/mL) & $0.99(0.96-1.02)$ & 0.435 & $1(0.96-1.04)$ & 0.890 \\
\hline Vitamin D supplementation & $0.96(0.33-2.77)$ & 0.936 & $1.04(0.13-1.05)$ & 0.971 \\
\hline Charlson-Deyo score ${ }^{1}$ & $0.97(0.79-1.2)$ & 0.805 & $0.63(0.39-1.03)$ & 0.065 \\
\hline Renal disease & $0.76(0.17-3.35)$ & 0.718 & & \\
\hline Malignancy & $1.28(0.45-3.66)$ & 0.646 & & \\
\hline ECF resident & $4.9(1.32-18.16)$ & 0.017 & $1.76(0.25-12.4)$ & 0.570 \\
\hline BMI & $1.01(0.94-1.08)$ & 0.82 & & \\
\hline Previous CDI & $0.92(0.54-1.6)$ & 0.77 & & \\
\hline Community associated & $1.31(0.32-5.4)$ & 0.710 & & \\
\hline HO-HA CDI & $1.74(0.65-4.70)$ & 0.273 & & \\
\hline Detection of stool toxin by EIA & $5.23(1.78-15.42)$ & 0.003 & $5.87(1.09-31.7)$ & 0.040 \\
\hline Infection with ribotype 014-020 & $1.06(0.27-4.19)$ & 0.933 & & \\
\hline Infection with ribotype 027 & $9.52(1.04-86.91)$ & 0.046 & NA & $>0.99$ \\
\hline Serum albumin (g/dL) & $0.18(0.05-0.66)$ & 0.010 & $0.12(0.02-0.64)$ & 0.013 \\
\hline
\end{tabular}

BMI, body mass index in $\mathrm{kg} / \mathrm{m}^{2} \mathrm{CDI}$, Clostridium difficile infection; $\mathrm{CI}$, confidence interval; ECF, extended care facility; EIA, enzyme immunoassay; HO-HA, healthcare facility-onset, healthcare facility-associated; OR, odds ratio; y, years. ${ }^{1}$ weighted comorbidity index.

Table 3. Unadjusted and adjusted Cox proportional-hazards analysis for independent predictors of recurrent disease.

\begin{tabular}{|c|c|c|c|c|}
\hline Characteristic & Unadjusted HR (95\%CI) & $\mathbf{P}$ & Adjusted HR (95\%CI) & $\mathbf{P}$ \\
\hline Age (years) & $1(0.98-1.02)$ & 0.910 & $1(0.98-1.03)$ & 0.844 \\
\hline Male gender & $1.18(0.54-2.58)$ & 0.686 & $1.15(0.35-3.76)$ & 0.819 \\
\hline Serum 25-hydroxyvitamin D (ng/mL) & $0.99(0.96-1.02)$ & 0.349 & $0.99(0.96-1.02)$ & 0.608 \\
\hline Vitamin D supplementation & $1.44(0.64-3.2)$ & 0.377 & $1.25(0.33-4.73)$ & 0.744 \\
\hline Charlson-Deyo score $^{1}$ & $1.04(0.9-1.2)$ & 0.617 & $0.94(0.72-1.24)$ & 0.680 \\
\hline ECF resident & $2.04(0.85-4.9)$ & 0.111 & $1.93(0.48-7.73)$ & 0.352 \\
\hline Previous CDI & $1.31(0.98-1.74)$ & 0.067 & $1.44(0.91-2.28)$ & 0.116 \\
\hline Detection of stool toxin by EIA & $2.05(0.90-4.66)$ & 0.088 & $1.12(0.38-3.34)$ & 0.835 \\
\hline Infection with ribotype 027 & $2.55(0.76-8.58)$ & 0.131 & $6.09(0.74-50.49)$ & 0.094 \\
\hline Serum albumin (g/dL) & $0.64(0.3-1.37)$ & 0.246 & $1.28(0.46-3.59)$ & 0.641 \\
\hline Severe disease & $1.5(0.68-3.31)$ & 0.316 & $1.21(0.37-3.89)$ & 0.754 \\
\hline
\end{tabular}

BMI, body mass index in kg/m²; CDI, Clostridium difficile infection; CI, confidence interval; ECF, extended care facility; EIA, enzyme immunoassay; HO-HA, healthcare facility-onset, healthcare facility-associated; HR, hazard ratio; y, years. ${ }^{1}$ weighted comorbidity index. 


\section{(39\%) participants.}

Risk factors for the development of the composite outcome of severe disease are shown in Tables 2 and 3. Serum 25-hydroxyvitamin D was not predictive of a severe outcome in unadjusted analysis [odds ratio (OR) 0.99; 95\% confidence interval (CI) 0.96-1.02, $\mathrm{P}=0.435$ ] or adjusted analysis (OR 1.00; 95\%CI 0.96-1.04, $\mathrm{P}=0.890$ ). Exogenous Vitamin D supplementation at the time of hospital admission was not predictive of the composite outcome in unadjusted analysis (OR $0.96 ; 95 \% \mathrm{CI}$ $0.33-2.77, \mathrm{P}=0.936)$ or adjusted analysis (OR 1.04; 95\%CI 0.13-1.05, $\mathrm{P}=0.971$ ). Risk factors for the development of severe disease on multivariate analysis included serum albumin (OR $0.12 ; 95 \% \mathrm{CI} 0.02-0.64, \mathrm{P}=0.013$ ) and diagnosis by EIA toxin (OR 5.87; 95\%CI 1.09-31.7, $\mathrm{P}=0.040$ ).

\section{Secondary outcomes}

Comparisons between mean serum 25hydroxyvitamin D and the categories of age, gender, season, ECF residence and exogenous vitamin D supplementation are shown in Figure 1. No significant differences were demonstrated between mean serum 25hydroxyvitamin $\mathrm{D}$ and season $(\mathrm{P}=0.89), \mathrm{ECF}$ residence $(\mathrm{P}=0.27)$ or age $(\mathrm{P}=0.4)$. Females demonstrated a trend toward higher serum 25hydroxyvitamin D levels $(\mathrm{P}=0.05)$ and individuals with exogenous vitamin D supplementation at the time of hospital admission demonstrated a statistically significant higher mean level of 25-hydroxyvitamin $\mathrm{D}(\mathrm{P}=0.01)$.

\section{Discussion}

This study examined the relationship between serum 25-hydroxyvitamin D and clinical outcomes in CDI. This study did not observe a relationship between serum 25hydroxyvitamin $\mathrm{D}$ at the time of $C$. difficile diagnosis and a composite clinical outcome including death, colectomy or ICU admission as clinical endpoints. Lending support to the generalizability of our conclusion regarding vitamin $\mathrm{D}$, our cohort retained a number of previously described risk factors for severe disease in unadjusted analysis: age, serum albumin, ECF residence, diagnosis by detection of stool toxin, and infection with the $C$. difficile strain ribotype 027..$^{18-20}$

In adjusting for the above factors in a multivariate model that included serum 25 -hydroxyvitamin D and gender, only serum albumin and diagnosis by detection of stool toxin by EIA retained statistical significance as independent predictors of severe disease. As serum albumin has consistently been described in studies assessing the development of CDI, adverse clinical outcomes, and recurrent dis- ease, validating this finding lends credence to our analysis. ${ }^{18,21}$ That detection of stool toxin by EIA was also predictive of severe disease in a multivariable analysis informs the current debate regarding the optimal laboratory method for diagnosis of CDI. ${ }^{22}$ Diagnosis by PCR cannot detect the presence of expressed $C$. difficile toxin and therefore cannot differentiate active disease from asymptomatic carriage in hospitalized patients, advocating for the use of multi-step algorithms. ${ }^{23}$ Although previous studies have drawn similar conclusions and correlated diagnosis with PCR to decreased CDI complications, not all studies have correlated toxin EIA status with clinical outcome. . $^{24,25}$

Vitamin D deficiency has been previously investigated in a study including 23 patients with CDI and 29 patients with methicillin-sensitive Staphylococcus aureus infections. Vitamin D deficiency ( $<20 \mathrm{ng} / \mathrm{mL}$ ) was associated with increased inpatient and outpatient healthcare costs, hospitalizations and length of stay. ${ }^{8}$ The study is limited by a lack of analysis for a direct association between vitamin D status and CDI clinical outcome, as well as a lack of control for confounding variables between vitamin $\mathrm{D}$ deficient and replete individuals, which would associate with the measured outcome of healthcare costs.

Several studies have previously examined the relationship between severe CDI and serum vitamin D level. With respect to acquisition of HO-HA CDI, Quraishi et al. retrospectively reviewed 568 patients who underwent $C$. difficile stool sample testing greater than 48 hours after admission in whom serum 25hydroxyvitamin D was assessed between 7 and 365 days prior to the hospitalization. Comparing those with preadmission 25hydroxyvitamin D levels $<10 \mathrm{ng} / \mathrm{mL}$ to those with levels $\geq 30 \mathrm{ng} / \mathrm{mL}$, there was an increased risk of HO-HA CDI (OR 2.90; 95\%CI 1.01-8.34, $\mathrm{P}=0.048) .{ }^{9}$ In another single center prospective study involving 100 hospitalized patients with CDI, severity was defined by the presence of abnormal computed tomography scan findings. Measured 25-hydroxyvitamin D3 was associated with severe CDI in a multivariable model that included age, Charlson-Deyo comorbidity index, vitamin D supplementation and recent hospitalization (OR $0.92 ; 95 \% \mathrm{CI}$ $0.87-0.98, \mathrm{P}=0.008) .{ }^{10}$ Finally, in a study of 62 hospitalized patients with a combined outcome of 30-day mortality or lack of resolution of diarrhea, patients with a low 25-hydroxyvitamin D $(<21 \mathrm{ng} / \mathrm{mL})$ demonstrated an increased association with severe disease (OR $4.75 ; 95 \%$ CI 1.18-19.1, $\mathrm{P}=0.028)$. The primary limitation to this endpoint and extrapolation to other studies involving CDI includes the unexpectedly high 30 -day mortality rate of $45.3 \%$ that was observed. ${ }^{11}$

Our study's hypothesis has biologic plausi- bility given the immunomodulatory role of vitamin D and that vitamin D status has been associated with a number of bacterial infections including outcomes in communityacquired pneumonia, ${ }^{7}$ bacterial vaginosis, ${ }^{26}$ and bacterial colonization in bronchiectasis. ${ }^{27}$ Activation of vitamin D first occurs in the liver to 25-hydroxyvitamin $\mathrm{D}$, which is then converted to its biologically active form 1,25-hydroxyvitamin $D$ by $1 \alpha$-hydroxylase. ${ }^{5}$ Expression of 1 -hydroxylase from its gene CYP27B1 is found in the kidney and in macrophages, where upregulation of expression can be induced by Toll-like receptor (TLR) activation., ${ }^{52}$ Final regulation of vitamin $\mathrm{D}$ induced transcriptional products is mediated through the binding of 1,25-hydroxyvitamin with a nuclear vitamin D receptor (VDR).

Although vitamin D has important implications on the immune response, colonic integrity, and outcomes in bacterial infections, we do not find an association between serum 25hydroxyvitamin D and clinical outcomes in hospitalized adults with CDI. To appropriately interpret these findings, several limitations need to be acknowledged. Serum samples were only available from 67 patients, thus it is possible that insufficient power was present and a type II error occurred. However, when performing a post-hoc power analysis our study had greater than $90 \%$ power to detect a $50 \%$ difference in the primary composite outcome [using the POWER procedure in SAS 9.3 (SAS Institute Inc., Cary, NC, USA)]. When limiting the primary outcome to severe disease (death, colectomy or ICU admission within 30 days), which occurred in six individuals, our study had greater than $90 \%$ power to detect a $75 \%$ difference in outcome. Secondly, we chose to measure 25-hydroxyvitamin D in this study given its routine clinical uses and approximate 3 week half-life. ${ }^{29,30}$ Unfortunately 25 -hydroxyvitamin D is a challenging analyte to accurately measure due to its lipophilic nature leading to strong affinity with vitamin D binding protein and serum albumin. ${ }^{31}$ We performed 25-hydroxyvitamin D measurement using a commercially available immunoassay with the ability to detect both 25-hydroxyvitamin D2 and 25-hydroxyvitamin D3, however external quality assessment was not performed. In comparison with previous studies, deficiency in 25-hydroxyvitamin D defined as $\leq 20 \mathrm{ng} / \mathrm{mL}$ was highly prevalent in this hospitalized population, 53/67 individuals (79\%), consistent with studies in severe COPD and acute myocardial infarction, ${ }^{32,33}$ providing support for the assay results obtained.

\section{Conclusions}

In summary, data from the present study 


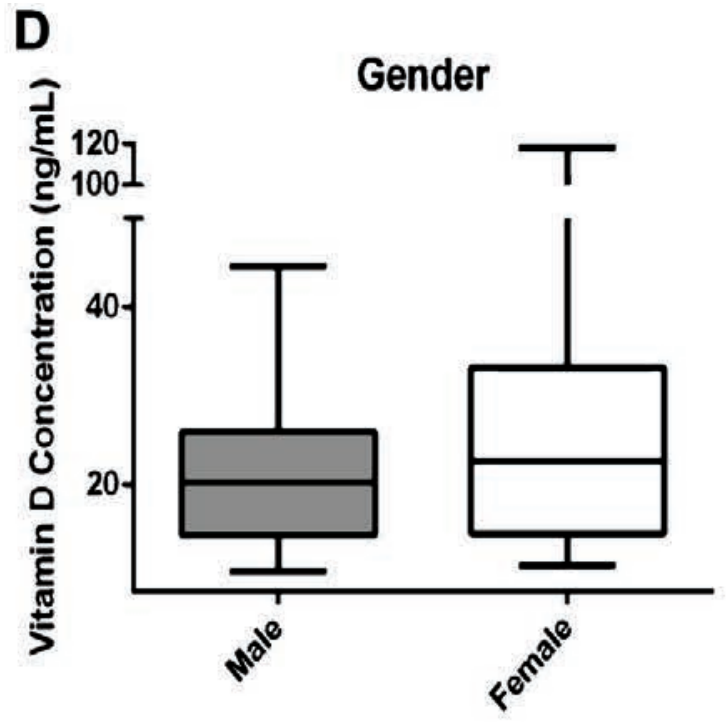

B
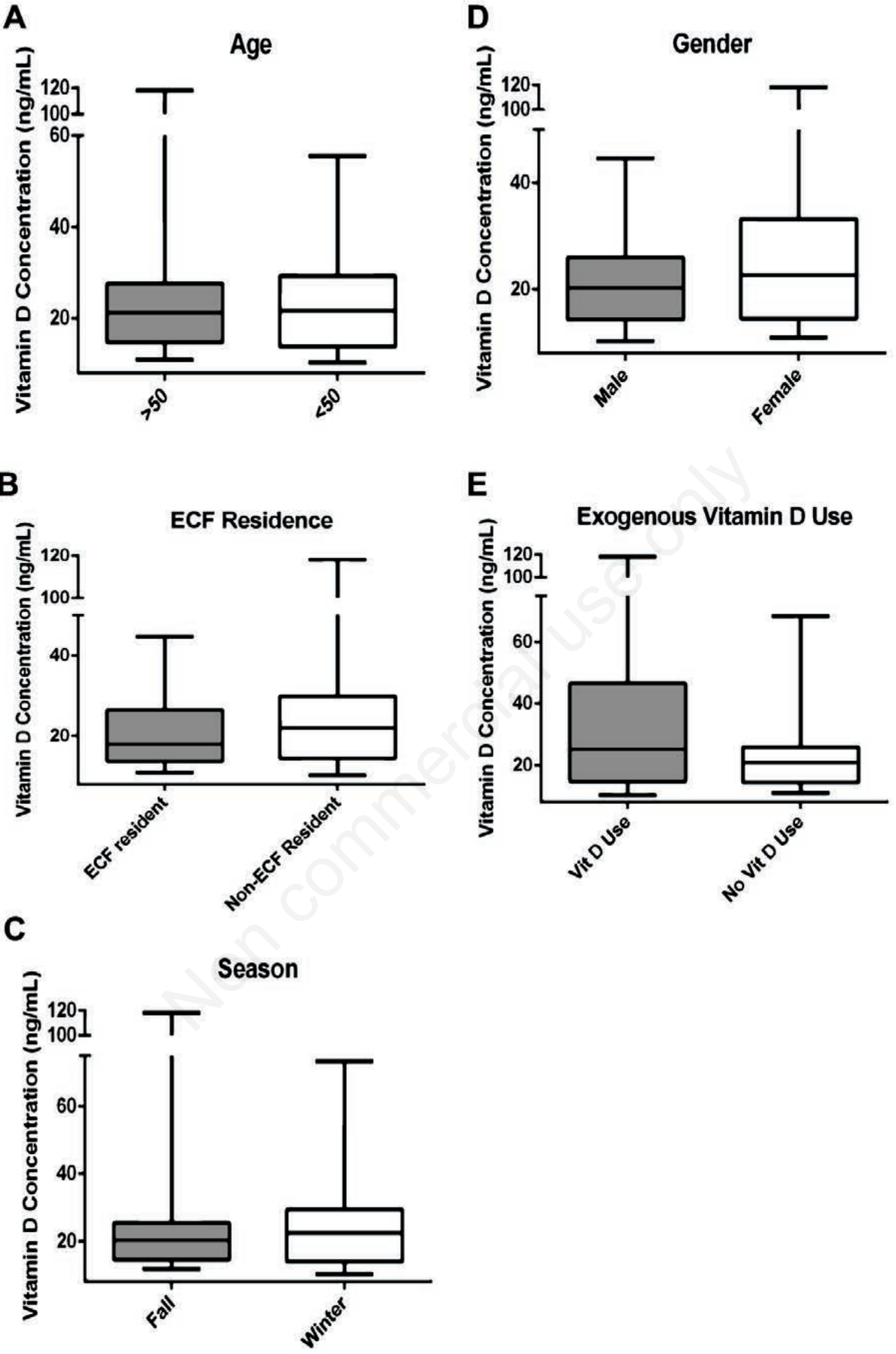

Figure 1. Serum 25-hydroxyvitamin D subgroup analysis. This figure compares mean serum 25-hydroxyvitamin D levels categorized by: A) age, B) extended care facility (ECF) residence, C) season, D) gender and E) exogenous vitamin D supplementation. Only exogenous vitamin $D$ supplementation demonstrated statistically significant higher levels of mean 25 -hydroxyvitamin $D(P=0.01)$. 
demonstrate a lack of association between serum 25-hydroxyvitamin D and adverse clinical outcomes in CDI. In an adjusted model for the prediction of severe disease, only serum albumin and diagnosis by detection of stool toxin by EIA remained statistically significant. Given the biologic plausibility for the role of vitamin $\mathrm{D}$ in $C$. difficile colitis, larger clinical studies assessing the role of vitamin D in the development, outcome, and recurrence of $C$. difficile are warranted.

\section{References}

1. Leffler DA, Lamont JT. Clostridium difficile infection. New Engl J Med 2015;372:153948.

2. Miller BA, Chen LF, Sexton DJ, Anderson DJ. Comparison of the burdens of hospitalonset, healthcare facility-associated Clostridium difficile Infection and of healthcare-associated infection due to methicillin-resistant Staphylococcus aureus in community hospitals. Infect Control Hosp Epidemiol 2011;32:387-90.

3. Dubberke ER, Olsen MA. Burden of Clostridium difficile on the healthcare system. Clin Infect Dis 2012;55:S88-92.

4. Musgrave CR, Bookstaver PB, Sutton SS, Miller AD. Use of alternative or adjuvant pharmacologic treatment strategies in the prevention and treatment of Clostridium difficile infection. Int $\mathrm{J}$ Infect Dis 2011;15:e438-48.

5. Ralph AR, Lucas RM, Norval M. Vitamin D and solar ultraviolet radiation in the risk and treatment of tuberculosis. Lancet Infect Dis 2013;13:77-88.

6. Campbell GR, Spector SA. Vitamin D inhibits human immunodeficiency virus type 1 and Mycobacterium tuberculosis infection in macrophages through the induction of autophagy. PLoS Pathogens 2012;8:e1002689.

7. Remmelts HH, van de Garde EM, Meijvis $\mathrm{SC}$, et al. Addition of vitamin D status to prognostic scores improves the prediction of outcome in community-acquired pneumonia. Clin Infect Dis 2012;55:1488-94.

8. Youssef D, Bailey B, El Abbassi A, et al. Healthcare costs of Staphylococcus aureus and Clostridium difficile infections in veterans: role of vitamin $D$ deficiency. Epidemiol and Infect 2010;138:1322-7.

9. Quraishi SA, Litonjua AA, Moromizato T, et al. Association between prehospital vitamin D status and hospital-acquired Clostridium difficile infections. JPEN J Parenter Enteral Nutr 2015;39:47-55

10. van der Wilden GM, Fagenholz PJ, Velmahos GC, et al. Vitamin D status and severity of Clostridium difficile infections: a prospective cohort study in hospitalized adults. JPEN J J Parenter Enteral Nutr 2015;39:465-70.

11. Wang WJ, Gray S, Sison C, et al. Low vitamin D level is an independent predictor of poor outcomes in Clostridium difficileassociated diarrhea. Therap Adv Gastroenterol 2014;7:14-9.

12. Rao K, Walk ST, Micic D, et al. Procalcitonin levels associate with severity of Clostridium difficile infection. PloS One 2013;8:e58265.

13. Walk ST, Micic D, Jain R, et al. Clostridium difficile ribotype does not predict severe infection. Clin Infect Dis 2012;55:1661-8.

14. McDonald LC, Coignard B, Dubberke E, et al. Recommendations for surveillance of Clostridium difficile-associated disease. Infect Control Hosp Epidemiol 2007;28: 140-5.

15. Deyo RA, Cherkin DC, Ciol MA. Adapting a clinical comorbidity index for use with ICD-9-CM administrative databases. J Clin Epidemiol 1992;45:613-9.

16. Charlson ME, Pompei P, Ales KL, MacKenzie CR. A new method of classifying prognostic comorbidity in longitudinal studies: development and validation. J Chronic Dis 1987;40:373-83.

17. Hoste EA, Clermont G, Kersten A, et al. RIFLE criteria for acute kidney injury are associated with hospital mortality in critically ill patients: a cohort analysis. Crit Care 2006;10:R73.

18. Henrich TJ, Krakower D, Bitton A, Yokoe DS. Clinical risk factors for severe Clostridium difficile-associated disease. Emerg Infect Dis 2009;15:415-22.

19. O'Connor JR, Johnson S, Gerding DN. Clostridium difficile infection caused by the epidemic BI/NAP1/027 strain. Gastroenterology 2009;136:1913-24.

20. Planche TD, Davies KA, Coen PG, et al. Differences in outcome according to Clostridium difficile testing method: a prospective multicentre diagnostic validation study of $\mathrm{C}$ difficile infection. Lancet Infect Dis 2013;13:936-45.

21. Abou Chakra CN, Pepin J, Valiquette L. Prediction tools for unfavourable out- comes in Clostridium difficile infection: a systematic review. PloS One 2012;7: e30258.

22. Wilcox MH, Planche T, Fang FC, Gilligan P. What is the current role of algorithmic approaches for diagnosis of Clostridium difficile infection? J Clin Microbiol 2010; 48:4347-53.

23. Wilcox MH. Overcoming barriers to effective recognition and diagnosis of Clostridium difficile infection. Clin Microbiol Infect 2012;18:13-20.

24. Longtin Y, Trottier S, Brochu G, et al. Impact of the type of diagnostic assay on Clostridium difficile infection and complication rates in a mandatory reporting program. Clin Infect Dis 2013;56:67-73.

25. Guerrero DM, Chou C, Jury LA, et al. Clinical and infection control implications of Clostridium difficile infection with negative enzyme immunoassay for toxin. Clin Infect Dis 2011;53:287-90.

26. Dunlop AL, Taylor RN, Tangpricha V, et al. Maternal vitamin D, folate, and polyunsaturated fatty acid status and bacterial vaginosis during pregnancy. Infect Dis Obstet Gynecol 2011;2011:216217.

27. Chalmers JD, McHugh BJ, Docherty C, et al. Vitamin-D deficiency is associated with chronic bacterial colonisation and disease severity in bronchiectasis. Thorax 2013; 68:39-47.

28. Liu PT, Stenger S, Li H, et al. Toll-like receptor triggering of a vitamin D-mediated human antimicrobial response. Science 2006;311:1770-3.

29. Cohen SH, Gerding DN, Johnson S, et al. Clinical practice guidelines for Clostridium difficile infection in adults: 2010 update by the society for healthcare epidemiology of America (SHEA) and the infectious diseases society of America (IDSA). Infect Control Hosp Epidemiol 2010;31:431-55.

30. Zerwekh JE. The measurement of vitamin D: analytical aspects. Ann Clin Biochem 2004;41:272-81.

31. Herrmann M. The measurement of 25 hydroxy vitamin D - an analytical challenge. Clin Chem Lab Med 2012;50:1873-5.

32. Puhan MA, Siebeling L, Frei A, et al. No association of 25-hydroxyvitamin D with exacerbations in primary care patients with COPD. Chest 2014;145:37-43.

33. Ng LL, Sandhu JK, Squire IB, et al. Vitamin $\mathrm{D}$ and prognosis in acute myocardial infarction. Int J Cardiol 2013;168:2341-6. 